\title{
Novo código florestal e reserva legal em propriedades rurais do município de Porto Alegre/RS
}

\author{
New forest code and legal reserve in rural properties of Porto Alegre/RS municipality
}

\author{
Lauro Marino Wollmann ${ }^{\mathrm{I}, \text { II }}$ Lia Caetano Bastos ${ }^{\mathrm{I}}$
}

\section{RESUMO}

$O$ atual Código Florestal inovou em diretrizes relacionadas à proteção da flora nativa. Estabeleceu regra especifica para os pequenos produtores rurais, para os quais a Reserva Legal ( $R L)$ pode ser regularizada com o percentual de remanescente de vegetação nativa existente em julho de 2008, caso este seja inferior a $20 \%$ da área. Nesse contexto, insere-se esta pesquisa, que tem por objetivo quantificar as Reservas Legais de 76 propriedades rurais, localizadas no extremo sul de Porto Alegrel $R S$, e caracterizá-las em termos de cobertura de vegetação nativa, de acordo com as disposições previstas no Código Florestal de 2012. Para tanto, foram utilizadas técnicas de geoprocessamento, através da utilização de mapas temáticos de vegetação e fundiário, integrados com os dados do cadastro imobiliário em um Sistema de Informação Geográfica. Dos 76 imóveis pesquisados, 18 possuem área acima de 04 Módulos Fiscais (MF), portanto, sua Reserva Legal foi calculada considerando $20 \%$ de sua área. Para as demais propriedades, a RL pode ser reduzida à sua fração de vegetação nativa, e constatou-se que somente 15 deles têm Reserva Legal menor que $20 \%$, variando, neste caso, de 1,8\% a 18,6\%. Reserva Legal sem cobertura de vegetação nativa foi constatada somente para o estrato onde se concentram os imóveis de maior tamanho. A regra especial isentou de recuperação da vegetação, por parte dos pequenos proprietários rurais, somente 1,4\% da área que deveria ser destinada a Reserva Legal, considerando as regras anteriores.

Palavras-chave: reserva legal, código florestal, vegetação nativa, propriedade rural.

\section{ABSTRACT}

The current Forest Code innovated in guidelines related to the protection of native flora. It established specific rule for small farmers, for which the Legal Reserve (RL) can be remedied with the percentage of remnant native vegetation existing in July 2008, if it is less than 20\% of the area. In this context fits into this research, which aims to quantify the legal reserves of 76 farms located in the extreme south of Porto Alegre/RS municipality, and characterize them in terms of coverage of native vegetation in accordance with the provisions of the Code Forest 2012. For both GIS techniques were used through the use of thematic maps of vegetation and land, integrated with data from the real estate cadastre in a Geographic Information System. 18 of the 76 properties surveyed have area above 04 Modules Tax (MF), therefore its legal reserve was calculated considering $20 \%$ of its area. For other properties, the RL can be reduced to a fraction of native vegetation, it was found that only 15 of them have less than $20 \%$ Legal Reserve, in this case ranging from 1.8\% to $18.6 \%$. Legal Reserve without native vegetation cover was observed only for stratum which concentrate the properties of larger size. The special rule exempting recovery of vegetation by small farmers only $1.4 \%$ of the area that should be allocated to the legal reserve considering the previous rules.

Key words: legal reserve, forest code, native vegetation, rural property.

\section{INTRODUÇÃO}

Ao longo do tempo, a estratégia governamental brasileira para garantir o uso sustentado dos recursos naturais em propriedades privadas foi baseada na adoção de medidas de comando e controle estabelecidas pelo Código Florestal, especialmente sob as formas de Áreas de Preservação Permanente e de Reservas Legais (AZEVEDO, 2008).

As Áreas de Preservação Permanente (APP), as Unidades de Conservação (UC) e a Reserva Legal (RL) são modalidades de espaço territorial especialmente protegido, de acordo com o artigo 225, parágrafo $1 \frac{\mathrm{o}}{\text { }}$ inciso III, da Constituição

\footnotetext{
IPrograma de Pós-graduação da Engenharia Civil, Universidade Federal de Santa Catarina (UFSC), Florianópolis, SC, Brasil.

IIPrefeitura Municipal de Porto Alegre, 90010-140, Porto Alegre, RS, Brasil. E-mail: lauromarino@hotmail.com. Autor para correspondência.
} 
Federal. Esta terminologia designa uma área sob regime especial de administração, com o objetivo de proteger os atributos ambientais justificadores do seu reconhecimento e individualização pelo Poder Público (COELHO JUNIOR, 2010).

A proteção de áreas representativas dos ecossistemas naturais de um determinado ambiente, no território brasileiro, tem raiz na criação do Código Florestal de 1934. Este Código apresentava algumas características preservacionistas, estabelecendo o uso da propriedade em função do tipo florestal existente. Já o Código de 1965 trouxe o conceito de florestas de preservação permanente, instituindo limitações à propriedade privada (BORGES et al., 2011).

O atual Código Florestal é composto pelas Leis 12.651/2012 (BRASIL, 2012) e 12.727/2012 (BRASIL, 2012b), confirmando e inovando nos conceitos relacionados à proteção da flora nativa. $\mathrm{O}$ Código determina que em todo imóvel rural deve ser mantida determinada área com cobertura de vegetação nativa, a título de Reserva Legal.

A Reserva Legal é definida no artigo 3을 inciso III, como a "área localizada no interior de uma propriedade rural com a função de assegurar o uso econômico de modo sustentável dos recursos naturais do imóvel rural, auxiliar a conservação e a reabilitação dos processos ecológicos e promover a conservação da biodiversidade, bem como o abrigo e a proteção de fauna silvestre e da flora nativa" (BRASIL, 2012). Implementada na propriedade, torna-se um instrumento fundamental para o uso sustentável dos recursos naturais (AVANCI, 2009; MELO NETO, 2013).

Aimplantação da Reserva Legal devebuscar a maximização do potencial agrícola da propriedade e a conservação da natureza (DELALIBERA et al., 2008). A interligação, na medida do possível, da área de Reserva Legal com os outros espaços protegidos será essencial para que sua função ambiental natural seja potencializada e cumprida, especialmente através de corredores ecológicos. É o caso, por exemplo, do fluxo gênico da flora e fauna que será mínimo ou insignificante, se restrito a uma área isolada da Reserva Legal (POLIZIO JUNIOR, 2012).

A partir do Código Florestal de 2012, no cálculo da área destinada à Reserva legal, podem ser somadas as Áreas de Preservação Permanente do imóvel, desde que o proprietário tenha requerido sua inclusão no Cadastro Ambiental Rural. Porém, o cômputo das APPs na área de Reserva Legal só é admitido se não implicar conversão de áreas de vegetação nativa e formações sucessoras para outras coberturas do solo, como atividades agropecuárias, industriais, assentamentos urbanos ou outras formas de ocupação humana. Além disso, a área a ser computada deve estar conservada ou em processo de recuperação, conforme comprovação do proprietário ao órgão estadual integrante do Sistema Nacional do Meio Ambiente (POLIZIO JUNIOR, 2012; MELO NETO, 2013).

A percentagem de cada propriedade ou posse rural que deve ser preservada com cobertura de vegetação nativa, a título de Reserva Legal, varia de acordo com a região e o bioma. O Código estabelece, no seu artigo 12, os tamanhos das Reservas: $80 \%$ em áreas de florestas da Amazônia Legal, 35\% no cerrado, $20 \%$ em campos gerais e em todos os biomas das demais regiões do País (BRASIL, 2012). Importante exceção à regra é apontada por POLIZIO JUNIOR (2012) e MUKAI (2013), quando destacam o estabelecido no artigo 67. Ou seja, para os imóveis de até 4 (quatro) módulos fiscais e que possuam remanescente de vegetação nativa em percentuais inferiores ao previsto no art. 12, a Reserva Legal será constituída com a área ocupada com a vegetação nativa existente em 22 de julho de 2008. Em decorrência dessa regra, caso o imóvel não tivesse área de vegetação nativa, este ficaria inclusive desobrigado do gravame de Reserva Legal.

Este dispositivo é dirigido aos pequenos proprietários rurais, uma vez que a Reserva Legal se mostrou inviável para estes, pois a área excedente não seria o suficiente ao plantio ou qualquer atividade econômica, além de ser altamente custosa para este tipo de proprietário. No entanto, reforça-se que esta regra não pode prosperar para as médias e grandes propriedades, que gozam das condições necessárias para o cumprimento integral da obrigação de reconstituição e recomposição da área de mata nativa (BRAGA, 2013).

Nesse contexto, esta pesquisa tem por objetivo quantificar a Reserva Legal de propriedades rurais localizadas no extremo sul de Porto Alegre e caracterizá-las em termos de cobertura de vegetação nativa, de acordo com as disposições previstas no novo Código Florestal de 2012.

\section{MATERIAL E MÉTODOS}

Para o estudo de caso, foi escolhida uma área no extremo sul do município de Porto Alegre, em função de suas características específicas e pela disponibilidade dos dados necessários.

Porto Alegre é a capital do Rio Grande do Sul, situando-se na Latitude Sul entre $29^{\circ} 10^{\prime} 30^{\prime \prime}$ e $30^{\circ} 10^{\prime} 00^{\prime \prime}$ e Longitude Oeste entre $51^{\circ} 05^{\prime} 00^{\prime \prime}$ e $51^{\circ} 16^{\prime} 15^{\prime}$ ". Possui uma área de $496,684 \mathrm{~km}^{2}$ e uma 
população de 1.409.351 habitantes (IBGE, 2010). Seu clima é classificado como subtropical úmido (Cfa, segundo Köppen), tendo como característica marcante a grande variabilidade dos elementos do tempo meteorológico. O município é recortado pelos biomas Pampa, em sua maior extensão, e também pela Mata Atlântica.

A área de estudo localiza-se no extremo sul do município de Porto Alegre, na Macrozona Rururbana. É banhada ao sul e sudoeste pelo Lago Guaíba. Aleste, faz divisa com o município de Viamão, em área de relevo ondulado e na maior parte coberta com remanescente de Mata Atlântica. O centro e o oeste são regiões planas, margeando o Lago Guaíba, onde se desenvolvem atividades de produção primária, especialmente de produção de arroz e agropecuária.

Para apuração da Reserva Legal, foram obtidos dados cadastrais fundiários e da cartografia municipal, que caracterizam as propriedades rurais em termos de tamanho, perímetro, localização geográfica junto à Prefeitura de Porto Alegre. Foram também obtidos dados da cobertura vegetal da área em estudo, com base em um levantamento aerofotogramétrico digital na escala 1.5.000, datado de agosto de 2010 .

Os imóveis foram classificados por tamanho em dois estratos: (a) até quatro módulos fiscais e (b) maior que quatro módulos fiscais. Cada estrato tem regra própria para determinação do tamanho da Reserva Legal. O módulo fiscal para o município de Porto Alegre é de cinco hectares, conforme Instrução Especial/INCRA n.20, de 28 de maio de 1980.

$\mathrm{Na}$ área em estudo, existem 356 imóveis rurais. A pesquisa foi realizada numa amostra de 76 propriedades rurais, determinada conforme metodologia proposta por BARBETTA et al, (2004), para um intervalo de confiança de $95 \%$ e erro amostral tolerável de $10 \%$. Os imóveis foram distribuídos proporcionalmente, de acordo com o número total de imóveis de cada estrato. Assim, obtiveram-se 18 imóveis no estrato acima de $04 \mathrm{MF}$ e 58 no estrato de até $04 \mathrm{MF}$. A escolha dos imóveis em cada estrato foi realizada de forma aleatória.

Os imóveis amostrados foram considerados todos como áreas rurais consolidadas para fins do disposto no Código Florestal, à medida que as atividades agrossilvipastoris nesta região remontam à longa data, confirmada especialmente pela análise de imagem orbital de 2007. Como cobertura de vegetação nativa, foram considerados os dados relativos a matas fornecidos pela Prefeitura de Porto Alegre. Os dados de vegetação referem-se a agosto de 2010 e, como eram os únicos disponíveis e em data bem próxima à necessária, estes foram utilizados para fins de apurar a vegetação nativa em julho de 2008 para cada imóvel.

Os dados do Cadastro Técnico foram integrados em um Sistema de Informação Geográfica (SIG) com a utilização do software ARCGIS, versão 10.2. Todos os dados foram referenciados ao SIRGAS 2000 (Sistema de Referência Geocêntrico para as Américas). Como produto final desta etapa de trabalho, foram gerados layers da estrutura fundiária (integrado com dados alfanuméricos do Cadastro Imobiliário) e da cobertura vegetal nativa.

O procedimento seguinte foi a determinação da cobertura de vegetação nativa de cada propriedade amostrada. Para tanto, no ambiente SIG, houve a intersecção do polígono de cada imóvel com o layer de vegetação, restando desta forma identificada a fração da cobertura vegetal nativa de cada imóvel.

O cálculo de Reserva Legal por imóvel considerou as várias regras constantes do Código Florestal. Com base nas premissas supracitadas, procedeu-se o dimensionamento da RL e sua caracterização em termos de cobertura de vegetação nativa, objetivo final do trabalho, cujos resultados são apresentados a seguir e analisados.

\section{RESULTADOS E DISCUSSÃO}

$\mathrm{Na}$ figura 1, está exemplificada a cobertura de vegetação nativa de alguns dos imóveis pesquisados, resultante da intersecção do layer de estrutura fundiária com o de vegetação nativa. Este cruzamento foi base para obtenção dos dados sumarizados na tabela 1, onde constam os quantitativos de área, vegetação nativa e Reserva Legal dos 76 imóveis rurais amostrados, por estrato.

Observa-se que, em média, a vegetação nativa ocupa $37,3 \%$ da área dos imóveis, chegando ao índice de $43,7 \%$ para os imóveis na faixa de até 04 módulos fiscais. Estes percentuais de vegetação nativa por propriedade denotam uma alta cobertura, em grande parte fruto do relevo acidentado existente na área pesquisada, o que dificulta a exploração de atividades agropecuárias.

A RL encontrada para a totalidade dos imóveis amostrados foi de 355,26ha, com a maior parcela $(81,6 \%)$ situada no estrato maior de $04 \mathrm{MF}$, que detém $80,5 \%$ da área total e somente $23,6 \%$ do número de imóveis. Se considerarmos a área total da Reserva Legal em relação à área total dos imóveis, a RL média ficou em 19,7\%, alcançando quase o limite máximo previsto na legislação, que é de $20 \%$.

Da área total de RL, 34,13 ha, isto é, 9,6\% não têm cobertura com vegetação nativa, devendo 


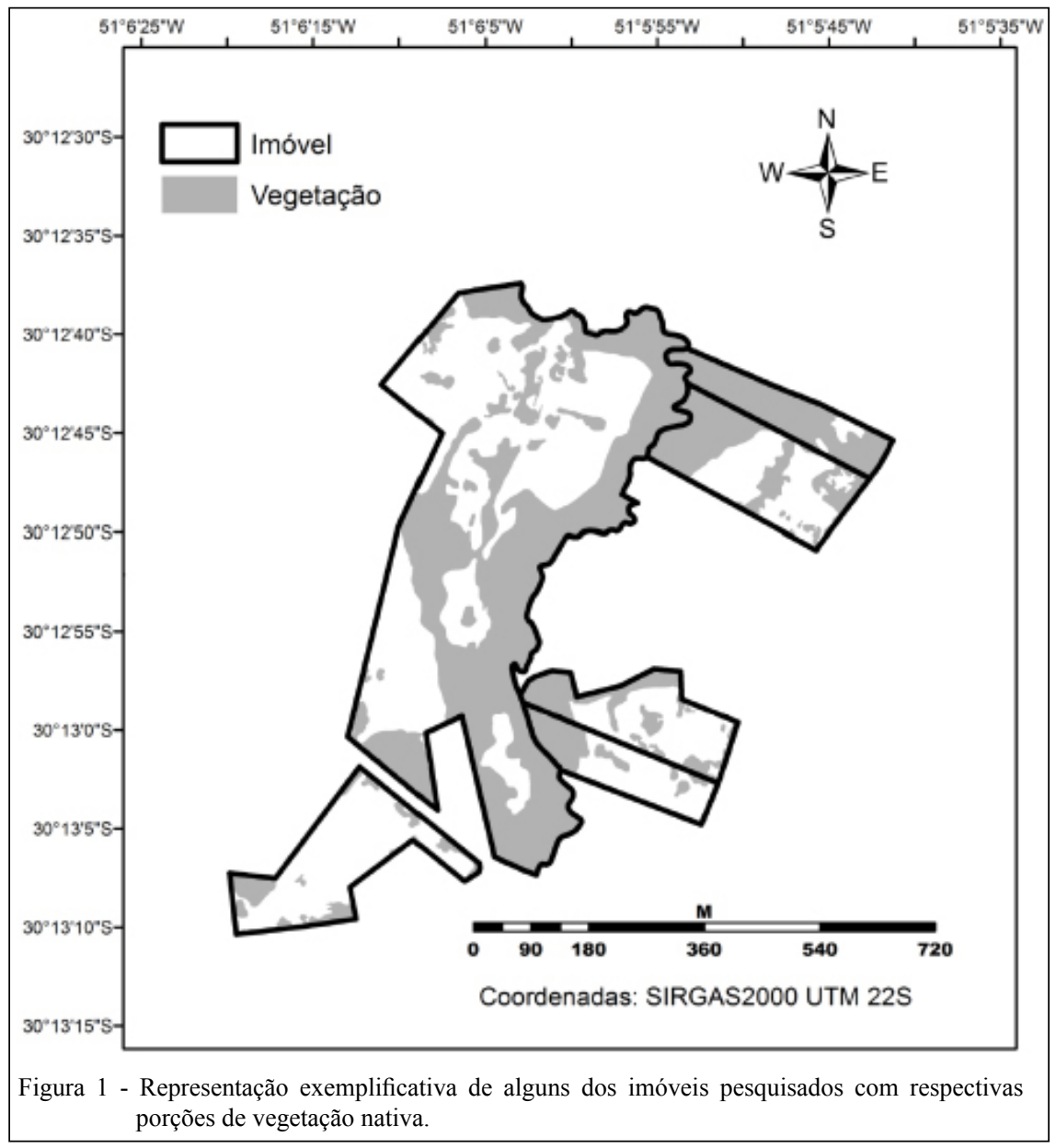

ser esta recuperada. Isto poderá ser feito conforme disposto no art. 66 do Código, recompondo a vegetação através do replantio ou permitindo a regeneração natural da vegetação ou, ainda, compensando a Reserva Legal em outra propriedade do mesmo bioma.

Considerando que a cobertura de vegetação nativa refletia a situação de julho de 2008 , constatou-se que imóveis com até 04MF não possuem Reserva Legal em desacordo com a legislação, sendo o efeito concreto do Código Florestal que definiu regra específica com possiblidade de redução da RL para imóveis até 04MF. A reposição da vegetação nativa para composição da Reserva Legal somente foi verificada no estrato onde se concentram os imóveis de maior tamanho.

Tabela 1 - Total de área, vegetação nativa e Reserva Legal dos 76 imóveis rurais amostrados por estrato.

\begin{tabular}{lclc}
\hline Parâmetros & até 04MF & maior 04MF & Total \\
\hline Quantidade de imóveis & 58 & 18 & 76 \\
Área dos imóveis - ha & 351,06 & $1.450,65$ \\
Vegetação nativa - ha & 153,68 & 518,95 & 34,1 \\
Vegetação nativa - \% da área & 43,8 & 290,04 \\
Reserva Legal - ha & 65,22 & 20,0 & 37,7 \\
Reserva Legal - \% da área & 18,6 & 255,91 \\
Reserva Legal com vegetação nativa - ha & 65,22 & 34,13 \\
Reserva Legal sem vegetação nativa - ha & 0,00 & 355,26 \\
\hline
\end{tabular}

Fonte: Prefeitura de Porto Alegre/RS.

Ciência Rural, v.45, n.3, mar, 2015. 
Na figura 2, é apresentado o percentual de Reserva Legal existente por imóvel. É possível verificar que imóveis no estrato acima de $04 \mathrm{MF}$ apresentam sua RL calculada em $20 \%$. Já no outro estrato, 15 imóveis do total de 58 apresentam Reserva Legal menor que $20 \%$, variando de $1,8 \%$ a $18,6 \%$. A média dos percentuais de RL em relação a todos os imóveis da pesquisa foi de $18,1 \%$.

A área total dos 76 imóveis componentes da pesquisa totalizou $1.801,71$ hectares, para uma Reserva Legal estimada de 355,26 hectares (Tabela 1). Caso não houvesse a regra especial para as pequenas propriedades rurais, a Reserva Legal seria de $20 \%$ para todos os imóveis, ou seja, um total de 360,34 hectares. Disso se depreende que a regra especial isentou de recuperação por parte dos pequenos produtores rurais uma área de 5,08 hectares, ou seja, somente 1,4\% da área que deveria ser destinada a Reserva Legal.

Os resultados obtidos mostram parte dos impactos introduzidos pelo novo Código Florestal nas regras ambientais anteriormente estabelecidas. Houve redução no tamanho da RL necessária nas pequenas propriedades rurais, no entanto, esta alteração, em termos de área, não se mostrou representativa. Por outro lado, propiciou a sua regularização perante as novas regras ambientais. Já em relação às médias e grandes propriedades (maiores que 04MF), não houve impacto em termos de redução de Reserva Legal.

As alterações na legislação ambiental promovidas pelo novo Código apontam para uma evidente diminuição na cobertura vegetal nativa, necessária na propriedade rural (FINK, 2013), o que se confirma com os resultados obtidos pela pesquisa. No entanto, outros aspectos que não foram objeto deste estudo podem colaborar substancialmente para este quadro. $\mathrm{O}$ novo Código inovou ao permitir a sobreposição das APPs com a RL. Reduziu também drasticamente a área de vegetação nativa obrigatória em áreas rurais consolidadas, decorrente de APPs definidas por elementos de hidrografia, de forma mais acentuada para as pequenas propriedades, mas também com efeitos para as médias e grandes (POLIZIO JUNIOR, 2012). Além disso, ampliou a possibilidade de ocupação dos topos de morro, montes, montanhas e serras, ao alterar os aumentos das alturas mínimas e da declividade limite para que a conservação de relevo deva ser objeto de delimitação de APP (OLIVEIRA E FERNANDES FILHO, 2013).

Assim, ao conjugarmos os efeitos no tamanho da RL com as regras estabelecidas para as APPs, será obtido o resultado das alterações introduzidas pelo novo Código, merecendo estudos complementares para se apurar o impacto efetivo final das novas regras em termos de vegetação nativa nas propriedades rurais. No entanto, é indiscutível que a adequada implementação da RL dá efetividade ao uso sustentável dos recursos naturais, a conservação e reabilitação dos processos ecológicos, a conservação da biodiversidade e a proteção da fauna e flora,

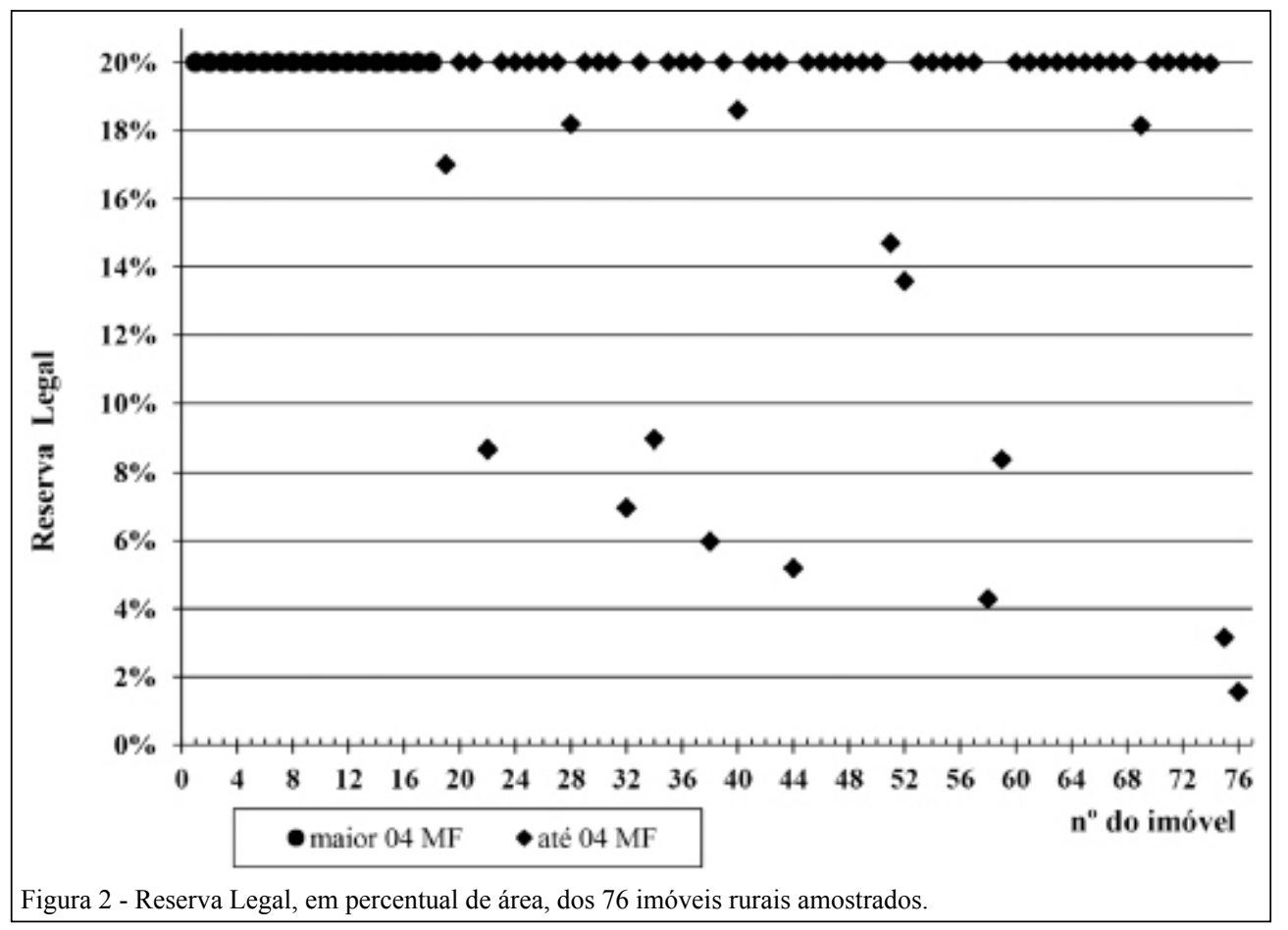

Ciência Rural, v.45, n.3, mar, 2015. 
dando maior concretude aos princípios da proteção da biodiversidade e da função socioambiental da propriedade rural (PEREIRA E D'OLIVEIRA, 2013).

\section{CONCLUSÃO}

O novo Código Florestal alterou as regras, em relação à Reserva Legal, para imóveis em áreas rurais consolidadas, buscando equacionar os ditames ambientais com o uso agrícola das propriedades.

Foi constada uma alta cobertura de vegetação nativa nas propriedades pesquisadas. As pequenas propriedades se encontram em situação regular em relação à Reserva Legal, em parte, como resultado da regra especial inserida no novo Código Florestal para este tipo de imóvel. No estrato das maiores propriedades, foram verificadas áreas destinadas à Reserva Legal sem a respectiva vegetação nativa, fato que, se não sanado nos prazos e condições estabelecidas, deixará a propriedade em situação irregular.

A conjugação dos efeitos da alteração das regras em relação à Reserva Legal com os preceitos estabelecidos para as áreas de Preservação Permanente, através de estudos complementares, permitirá apurar o impacto efetivo das alterações promovidas pelo novo Código Florestal em termos de vegetação nativa nas propriedades rurais.

\section{AGRADECIMENTO}

À Prefeitura de Porto Alegre, pela cessão de dados necessários à realização da pesquisa.

\section{REFERÊNCIAS}

AVANCI, T.F.S. A reserva legal como instrumento de efetividade da proteção da biodiversidade. Revista USCS - Direito, São Caetano do Sul, ano X, n.17, p.187-209, 2009. Disponível em: <http://seer. uscs.edu.br/index.php/revista_direito/article/view/926>. Acesso em: 25 maio 2013. doi: 10.13037/dh.n17.926.

AZEVEDO, T.S. de. Legislação e Geotecnologias na Definição das Áreas de Preservação Permanente e das Reservas Legais: aplicação à Bacia do Córrego das Posses, Município de Extrema - MG. 2008. 168f. Tese (Doutorado em Geografia) - Instituto de Geociências e Ciências Exatas, Universidade Estadual Paulista, Rio Claro, SP.

BARBETTA, P.A. et al. Estatística para Cursos de Engenharia e Informática. São Paulo: Atlas, 2004. 376p.

BORGES, L.A.C. et al. Áreas de preservação permanente na legislação ambiental brasileira. Ciência Rural, v.41, p.12021210, 2011. Disponível em: <http://dx.doi.org/10.1590/S010384782011000700016>. Acesso em 10 dez. 2013. doi: 10.1590/ S0103-84782011000700016.
BRAGA, R.B. Disposições Transitórias. In: MILARE, E.; MACHADO, P.A.L. (Orgs.). Novo Código Florestal: Comentário à Lei 12.651 , de 25 de maio de 2012, à Lei 12.727 , de 17 de outubro de 2012. 2.ed. São Paulo: Rev. dos Tribunais, 2013. Cap. XIII, p.484-487.

BRASIL. Lei n. 12.651, de 25 de maio de 2012. Dispõe sobre a proteção da vegetação nativa; altera as Leis nos 6.938, de 31 de agosto de 1981, 9.393, de 19 de dezembro de 1996, e 11.428, de 22 de dezembro de 2006; revoga as Leis nos 4.771, de 15 de setembro de 1965, e 7.754, de 14 de abril de 1989, e a Medida Provisória no 2.166-67, de 24 de agosto de 2001; e dá outras providências. 2012. Diário Oficial da União, Brasília, DF, Ano CXLIX, n. 102, 28 maio 2012. Seção 1, p.1. Disponível em $<$ http://portal.in.gov. br/>. Acesso em 10 março de 2013.

Lei n. 12.727, de 17 de outubro de 2012. Altera a Lei no 12.651 , de 25 de maio de 2012, que dispõe sobre a proteção da vegetação nativa. 2012a. Diário Oficial da União, Brasília, DF, Ano CXLIX, n. 202, 18 outubro 2012. Seção 1, p.1. Disponível em $<$ http://portal.in.gov.br/>. Acesso em 10 março de 2013.

COELHO JUNIOR, L. Intervenções nas áreas de preservação permanente em zona urbana: uma discussão crítica acerca das possibilidades de regularização. Revista Custus Legis, v.2, p.131,2010 .

DELALIBERA, H.C. et al. Alocação de reserva legal em propriedades rurais: Do cartesiano ao holístico. Revista Brasileira de Engenharia Agrícola e Ambiental, v.12, n.3, p.286-292, 2008. Disponível em: <http://dx.doi.org/10.1590/ S1415-43662008000300010>. Acesso em 01 agosto 2013. doi: 10.1590/S1415-43662008000300010.

FINK, D.R. Das áreas rurais consolidadas em áreas de reserva legal. In: MILARE, E.; MACHADO, P.A.L. (Orgs.). Novo Código Florestal: Comentário à Lei 12.651 , de 25 de maio de 2012, à Lei 12.727, de 17 de outubro de 2012. 2.ed. São Paulo: Rev. dos Tribunais, 2013. p.470-483.

IBGE (INSTITUTO BRASILEIRO DE GEOGRAFIA E ESTATÍSTICA). Censo Demográfico 2010. Disponível em: $<$ http://www.censo2010.ibge.gov.br>. Acesso em: 25 nov. 2013.

MELO NETO, J.E. Das disposições gerais incisos III a V e X. In: MILARE, E.; MACHADO, P.A.L. (Orgs.). Novo Código Florestal: Comentário à Lei 12.651, de 25 de maio de 2012, à Lei 12.727, de 17 de outubro de 2012. 2.ed. São Paulo: Rev. dos Tribunais, 2013. p.166-141.

MUKAI, T. O novo código florestal: notações à Lei $\mathrm{n}^{\circ} 12.651$, de 25 de maio de 2012, coma as alterações da Lei 12.727, de 17 de outubro de 2012, de 17 de outubro de 2012. Rio de Janeiro: Forense, 2013. 162p.

OLIVEIRA, G.C.; FERNANDES FILHO, E.I. Metodologia para delimitação de APPs em topos de morros segundo o novo Código Florestal brasileiro utilizando sistemas de informação geográfica. In: Anais SIMPÓSIO BRASILEIRO DE SENSORIAMENTO REMOTO, 16., Foz do Iguaçu, PR 2013. Anais... Foz do Iguaçu/ PR: INPE, 2013. p.4443-4450.

PEREIRA, M.S.; D'OLIVEIRA, R.L.D. Do regime de proteção da reserva legal. In: MILARE, E.; MACHADO, P.A.L. (Orgs.). Novo código florestal: comentário à Lei 12.651 , de 25 de maio de 2012, à Lei 12.727, de 17 de outubro de 2012. 2.ed. São Paulo: Rev. dos Tribunais, 2013. p.259-271.

POLIZIO JUNIOR, V. Código florestal - comentado, anotado e comparado. São Paulo: Rideel, 2012. 436p. 